\title{
Refractory Seizures and Difficult Venous Cannulation: An Intensivist Nightmare!
}

\author{
Varun Jain ${ }^{1}$ Harsh Sapra ${ }^{2}$ Atamaram Bansal ${ }^{3}$ \\ ${ }^{1}$ Department of Neuroanaesthesiology and Critical Care, All India \\ Institute of Medical Sciences, New Delhi, India \\ ${ }^{2}$ Department of Neuroanaesthesia and Critical Care, \\ Medanta-The Medicity, Gurugram, Haryana, India \\ ${ }^{3}$ Department of Neurology, Medanta-The Medicity, Gurugram, \\ Haryana, India
}

J Neuroanaesthesiol Crit Care 2018;5:123-124.

We present a case of 19-year-old woman (weighing $110 \mathrm{~kg}$, $180 \mathrm{~cm}$ height, muscular built), in refractory seizure with difficult intravenous cannulation. She was a known case of epilepsy since 4 years of age and had delayed milestones. She underwent deep brain stimulation (DBS) surgery in October 2013 for the same reason and was well controlled on phenytoin and levetiracetam until 3 weeks back. Since 3 weeks, her seizure frequency (tonic) had progressively increased from one to two episodes in a month to approximately two to three episodes every 5 minutes lasting for 10 to 15 seconds now.

When patient was received at midnight, she was restless and agitated from her long journey from Zambia to New Delhi. She had a conspicuous language barrier and only understood her mother. It was decided to start her on a loading dose of phenytoin and levetiracetam, and that is when the trouble started. We were unable to gain intravenous access. The patient had dark skin texture and collapsed veins due to dehydration. After a few failed attempts of cannulation, she started to get furious at the mere sight of venous cannula and even started to throw the cannulas at us and made attempts to bite. It was only possible to attempt cannulation during her episodes of seizure. However, those short windows of few seconds were not helpful.

We took parental permission to sedate her using intramuscular midazolam and attempt cannulation. However, this attempt backfired, as even after three $5 \mathrm{mg}$ intramuscular midazolam injections, her seizures did not disappear but decreased in frequency making our chances of attempting cannulation fewer. They made her drowsy and more irritable because she was unable to sleep. Fortunately, her airway and breathing were never compromised. She did not allow us to apply pulse oximeter, but we kept an oxygen mask at $10 \mathrm{~L} / \mathrm{min}$ flow near the head end of the bed. Every prick made her more agitated. At times she snatched the cannula and

\begin{abstract}
Address for correspondence Varun Jain, MBBS, MD, DNB, DM, Department of Neuroanaesthesiology and Critical Care, Room No 711, CNC, All India Institute of Medical Sciences, New Delhi. 110029, India (e-mail: varunj2202@gmail.com).
\end{abstract}

tried to poke the staff with it. We decided to put a femoral line in her. However, despite eight nursing staff trying to restrain her, she overpowered them and no number of restrains on the patient were enough.

Finally, when nothing worked, a call was taken to bring an anesthesia workstation from operating theater (OT) to intensive care unit (ICU). During her one episode of seizure, we managed to anesthetize the patient on a mask, preprimed with sevoflurane. We supported her ventilation with intermittent positive-pressure ventilation. Neurosurgical team attempted a venous cut-down on the ankle (for great saphenous vein) but were unsuccessful. We inserted right internal jugular central venous catheter under ultrasound guidance, and finally after 3 hours of struggle, we were able to gain a venous access.

The patient was then loaded with antiepileptics (phenytoin $2 \mathrm{~g}$ and levetiracetam $1.5 \mathrm{~g}$ ) and started on propofol infusion. She remained on low sedating dose of propofol (at $100-200 \mathrm{mg} / \mathrm{h}$ ) for 4 days to keep her at a Richmond Agitation Sedation Score of -1 to -2 . She did not need any respiratory support during this time. It was realized that seizure frequency was coinciding with DBS signaling. During her 6-day stay in ICU, video electroencephalography (VEEG) was done four times, and antiepileptics and DBS setting were adjusted three times. At the end of sixth day, her seizures were well controlled. The patient was discharged on seventh day with advice for regular follow-up.

We here highlight the fact that in such a crisis situation, inhalational anesthesia helped us calm a patient. Sedating with inhalational agents is a known method for intravenous cannulation for children in OT. However, no inhalational agent is currently approved for ICU sedation, but various off-label uses are in progress. ${ }^{1}$ We suggest that ICUs (especially those manned by anesthesiologist) should have an anesthesia workstation present or available for standby use from OT,

\section{received}

March 1, 2018

accepted

May 17, 2018

published online

June 16, 2018
DOI https://doi.org/

10.1055/s-0038-1660960

ISSN 2348-0548.
Copyright (c)2018 Indian Society of Neuroanaesthesiology and Critical Care
License terms

() (1) $\ominus \circledast$ 
for providing short procedural sedation or to overcome such a crisis situation. Various algorithms of gaining peripheral venous access involving ultrasonography, ${ }^{2}$ infrared lights ${ }^{3}$ are not useful when the patient is not cooperative. Inhalational agent might seem the extreme end, but it surely is the quickest way to calm a patient with no intravenous access.

\section{Conflict of Interest}

None.

\section{References}

1 Misra S, Koshy T. A review of the practice of sedation with inhalational anaesthetics in the intensive care unit with the AnaConDa( $\left({ }^{\circledR}\right)$ device. Indian J Anaesth 2012;56(6):518-523

2 Mbamalu D, Banerjee A. Methods of obtaining peripheral venous access in difficult situations. Postgrad Med J 1999;75(886):459-462

3 Lamperti M, Pittiruti M II. II. Difficult peripheral veins: turn on the lights. Br J Anaesth 2013;110(6):888-891 